\title{
Measuring the therapeutic efficacy of coronary revascularization: Implications for future management
}

\author{
J. Scott Rankin, MD, and Frank E. Harrell, Jr, PhD
}

See related article on page 1021 .

"In certain cases of angina pectoris, when the mouth of the coronary arteries is calcified, it would be useful to establish a complementary circulation for the lower part of the arteries."

Alexis Carrell, 1910

From the Centennial Medical Center, Vanderbilt University, Nashville, TN.

Received for publication Nov 23, 2005; revisions received Dec 28, 2005; accepted for publication Dec 30, 2005.

Address for reprints: J. Scott Rankin, MD, Vanderbilt University, 2400 Patterson Street, Suite 103, Nashville, TN 37203 (E-mail: Jsrankinmd@cs.com).

J Thorac Cardiovasc Surg 2006;131:944-8 $0022-5223 / \$ 32.00$

Copyright $\odot 2006$ by The American Association for Thoracic Surgery

doi:10.1016/j.jtcvs.2005.12.039
$\mathrm{T}$

The concept of coronary revascularization has existed for a century now, since Alexis Carrell's seminal experimental procedure, in which the left subclavian artery was suture-anastomosed to the circumflex coronary artery in the dog. ${ }^{1,2}$ The latter half of the century witnessed an explosion in techniques of coronary revascularization, both in cardiac surgery and interventional cardiology. With analysis of long-term outcomes, the clinical benefits of restoring coronary flow are now well-established, including improved quality of life and better long-term survival. In the past decade, however, multiple methods of coronary revascularization have emerged, creating confusion about the best technique in a given patient. Clinical approaches have been on a veritable roller coaster, leading to fractionation of therapeutic recommendations and controversy. As stated by Dr. John W. Kirklin in his 1972 Lewis A. Conner lecture before the American Heart Association ${ }^{3}$ : "When [physicians] embark upon an intervention for their patient, they must do so with confidence and conviction if there is to be a high probability of success. But these very convictions can make the doctor guilty of premature conviction in evaluating procedures, unless he addresses this evaluation with the same seriousness and skill he uses in treating individual patients". With recent objective assessments, fairly uniform data now are emerging to guide decision-making, and relevant issues (and at least some answers) are becoming more consistent. The purpose of this editorial is to review briefly this new information, within the context of the article in this issue by Guru and associates ${ }^{4}$ and to present a viewpoint, based on the authors' interpretation of current data.

Very early after the clinical introduction of surgical coronary bypass, a major study was begun, the Veterans Administration (VA) randomized trial. ${ }^{5}$ It should be emphasized that this was an early era both in clinical research and in the techniques of coronary bypass. We now forget that the first major randomized trial in surgery had been published only a few years earlier, ${ }^{6}$ and that statistical methods such as the Cox model for observational studies had not yet been described. ${ }^{7}$ By today's standards, surgical techniques for coronary bypass also were rudimentary. Despite these limitations, the VA trial did show a significant survival benefit after coronary bypass in patients with left main coronary disease, primarily because the surgical/ medical treatment benefit was so large that it could be defined even with a small sample. The next 3 major trials were: 1) the Unstable Angina Trial, 2) the European Coronary Surgery Study, and 3) the Coronary Artery Surgery Study (CASS). Each of these trials examined coronary bypass versus medical therapy in non-left main patients with predominantly good ventricular function, each had recruitment problems, and all probably were underpowered. ${ }^{8-10}$ Moreover, the results of these trials, arguably, were interpreted in over-simplified and possibly counterproductive ways, ${ }^{11}$ to support the concept that coronary bypass had no survival benefit in non-left main patients and to suggest that a delayed approach to coronary revascularization was appropriate in most situations. These studies also illustrated the 
limitations of randomized trials in cardiovascular disease: excessive cost, recruitment difficulties, selection of potentially unrepresentative patients at the point of randomization, the necessity of crossover design for patient care (and its negative effects on statistical power), the ability to assess treatment at only one point in time, and the potential for superficial misinterpretation of the data. To this list can be added new problems encountered in more recent trials, such as STICH: the reluctance of physicians to contribute patients in a financially stressed environment and the now excessive cost of malpractice insurance for prospective clinical research. While randomized study design minimizes baseline differences and confounding influences in patient cohorts, it should not be viewed (as in the Guru paper) as any type of "gold standard". Randomized clinical trials require proper scrutiny and interpretation, just like any other clinical research.

By the mid-1980's, statistical methodology for observational studies had improved considerably, especially with the development of the Cox proportional hazards model. When coupled with prospective data collection, such as employed in Duke Cardiovascular Databank studies, the Cox model allowed entire clinical populations to be assessed, at minimal additional cost, over extended periods of time, and with better understanding of (and compensation for) treatment selection biases. Hlatky and associates ${ }^{12}$ demonstrated that in a well-understood area such as coronary artery disease, and with the availability of powerful prognostic variables, an inclusive patient cohort, and nearly complete followup, predictions of survival with medical versus surgical therapies were in excellent agreement between randomized and observational publications. Observational methodology, to be sure, also had limitations, but by 1984, the results suggested a significant survival benefit after coronary bypass grafting in all patients with multi-vessel coronary artery disease. ${ }^{13}$ Interestingly in the Duke data, surgical survival characteristics have been stable since the mid-80's (unpublished observations, Dr. Peter K. Smith and Mr. Robert Tuttle, 2005), and early studies designed to assess the clinical benefits of multiple internal mammary artery (IMA) bypass grafting proved negative at initial follow-up. ${ }^{14}$

More recent surgical innovation addressed the potential advantages of off-pump coronary bypass. While this method had been used for some time, a major effort was made to improve technical details and to extend the procedure into patients with more complex disease. With considerable data coming in at present, ${ }^{15}$ off-pump bypass probably improves early results negligibly, and several studies suggest that long-term outcomes could be inferior, ${ }^{16,17}$ perhaps because of problems with myocardial protection, the tendency to under-graft, and at times, compromised graft quality. While this subject is still unresolved and is undergoing considerable debate, in the author's view, off-pump bypass probably will not be associated with large advantages in the management of patients with coronary artery disease.

Another major effort at quality improvement was the development of percutaneous coronary interventions (PCI). Evolving over 2 decades from balloon angioplasty alone, to atherectomy, to bare-metal stents, and now to drug eluting stents, PCI has engendered an enormous developmental effort on the part of industry and cardiology investigators. This evolution has been accompanied by a reduction in early complications, to the point that PCI procedures now are rarely associated with acute problems. Advanced interventional techniques have contributed significantly to the care of patients with acute myocardial infarction and other acute coronary syndromes. Because of the perception that restenosis rates are much lower (a concept based primarily on 6-12 month follow-up data), drug eluting stents currently are being used in increasingly complex clinical settings, to the point that national rates of coronary bypass surgery are falling. PCI does have the advantage of less invasive methodology and diminished patient trauma, but do the available long-term clinical data justify this massive expansion in application?

In BARI trial studies of balloon angioplasty, ${ }^{18}$ and also in more recent analyses of bare metal stents, ${ }^{19,20,21,22}$ longterm death rates after PCI were significantly higher than those observed for coronary bypass. Along these lines, the BARI trial illustrated several points. First, like CASS, BARI largely enrolled low-risk patients with good outcomes. With low event rates, therapeutic differences may have been difficult to define with the trial sample size. At the outset, the surgical committee of BARI (chaired by Dr. Floyd Loop) was concerned about this problem, and negotiated for liberalizing enrollment criteria. Ultimately, the concept emerged from BARI that coronary bypass was more effective than PCI only in diabetics, based on a positive treatment interaction term $(P=0.042)$. However, it is also possible that "diabetes" was a surrogate for higher general baseline risk, and that the surgical outcome benefit in diabetics was a reflection (to some extent) of better results in the higher risk population. ${ }^{18}$ The more recent concept that PCI is associated with twice the relative longterm death rate as coronary bypass across the entire spectrum of baseline risk (manifested as small absolute differences in low-risk patients and large absolute differences in high-risk patients) may be the operative principle. ${ }^{19,22}$ This sobering fact should bring pause to the general application of PCI, especially considering the projected number of patients who may have died because of PCI over-utilization. Assessment of drug-eluting stents is under-way at present, most notably in the BARI 2D trial, comparing medical with surgical and PCI therapies in patients with Type 2 diabetes. The beginning of this trial fortuitously coincided with the introduction of drug eluting stents; the results, therefore, 


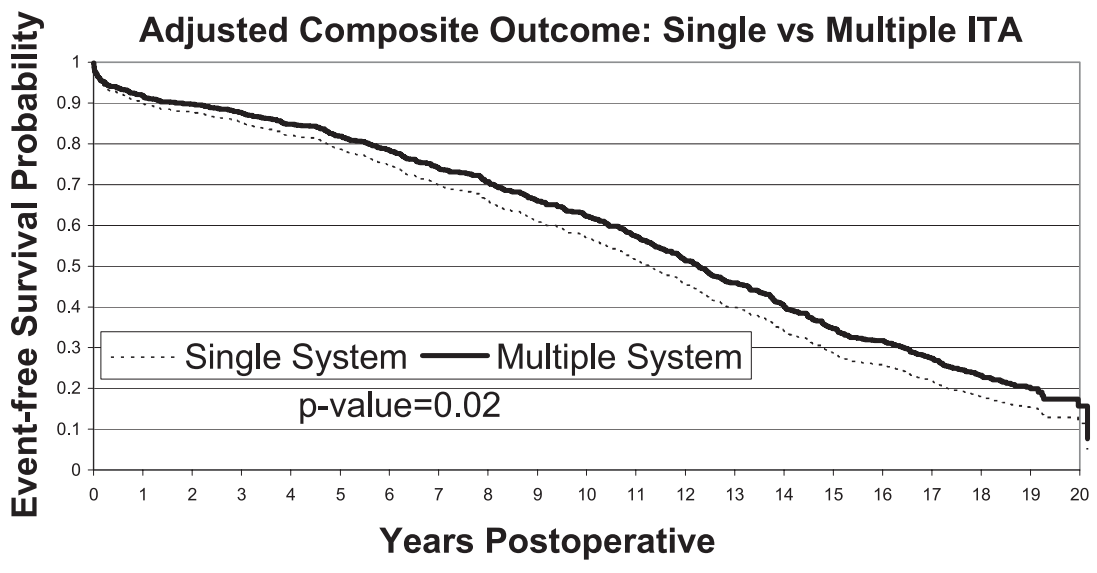

Figure 1. Composite outcomes of all-cause mortality, non-fatal $\mathrm{MI}, \mathrm{PCI}$, and redo coronary bypass were significantly reduced in multivessel coronary disease patients undergoing multiple IMA grafting to 2 different coronary systems (as compared to single IMA grafting) at 20 -years of followup.

will be very important; and 3-year outcomes in BARI 2D should be available shortly. The concept of "hybrid" coronary revascularization, utilizing combinations of minimally invasive IMA grafts and simultaneously placed coronary stents, is a recent variation on the PCI theme. It is likely that the poor performance of coronary stents may be a limiting factor with this approach, ${ }^{23}$ but more long-term data are needed. Finally, the problem of late sudden death seen with drug eluting stents in clinical practice is very concerning, and it is hoped that scientific data will soon be available as a guide. Many are concerned that self-referral and financial incentives have played at least some role in the rapid expansion of PCI, and it would be useful to recall Dr. Kirklin's admonitions when considering future therapeutic options.

Throughout this evolution of approaches, Dr. Bruce Lytle and associates at the Cleveland Clinic continued to espouse the advantages of bilateral internal thoracic artery bypass. ${ }^{24,25}$ Even when most data were to the contrary, Drs. Lytle and Blackstone applied a newer observational technique, propensity score matching, to the assessment of this problem. Propensity analysis has been a breakthrough in comparing treatments in observational studies. ${ }^{26-28}$ By liberally modeling tendencies for non-random treatment selection using all available baseline variables (significant or not), the propensity model (estimated probability that a patient will get a specific treatment) captures all measured confounders into a single variable. Propensity analysis can be considered a data reduction technique in which more confounders can be adjusted than there are deaths. It can be accompanied by a sensitivity analysis to assess whether an observed treatment effect can easily be explained by an unmeasured confounder; thus, propensity modeling allows much more aggressive adjustment for confounding variables than previously possible. Using these methods, data from multiple sources are becoming available, including the paper of Guru and associates, and most studies verify Dr. Lytle's hypothesis. Dr. Guru's analysis also illustrates several important design innovations, including the linking of multiple national da- tabases. While refinements will need to be made, employing a similar technique of linking the ACC and STS databases to the National Death Index could facilitate clinical cardiovascular research in heretofore unimagined ways. It would be necessary to fulfill HIPAA requirements in order to maintain patient identifiers in the STS database, but efforts should begin in this direction. Additionally, consideration should be given to using the STS database as the platform for generating more cost-effective randomized trials in cardiac surgery. Since the first goal of establishing the STS database has been achieved, future modifications might be directed toward significantly enhancing national clinical research. The key is continued improvement in database accuracy, validity, and completeness.

The Guru study also illustrates the importance of composite outcomes. It is now understood that outcomes are multivariate and inter-related, as in the concept of competing risks. ${ }^{29}$ These new insights and other very important improvements in observational analyses are in their early development. An example is analysis of dynamic or timevarying treatments. It is often the case that a treatment cannot be assigned to patients at the time of diagnosis without subsequent additional therapies being applied or withdrawn. Thus, attempting to compare dynamic treatment regimens can be extremely difficult. Some promising methods, ${ }^{30-32}$ including time-varying propensity scores, are now available and undoubtedly will be applied to the complex situations seen in current practice. Highly sophisticated observational approaches, performed on large and comprehensive patient populations, offer great promise for the future, and as these methods are developed, the current trend toward generalizing research at the national level could rapidly accelerate clinical observations. Needless to say, the availability of virtually on-line, large-scale, and even more precise national databases in every aspect of cardiovascular disease could bring the reality of "evidencebased medicine" to daily bed-side decision making. 
Returning to the Guru paper, few now would question the benefits of multiple IMA bypass in patients with multivessel coronary disease. Long-term mortality is reduced, non-fatal myocardial infarction and PCI occur at a lower rate, and the incidence of reoperation is dramatically less. ${ }^{33}$ In the authors' study (Figure 1) with a mean follow-up to 20 -years, ${ }^{34}$ average event-free life expectancy was extended by almost one year, and on average, one patient in five benefited clinically. Only $4.6 \%$ of multi-vessel patients undergoing multiple IMA grafting required redo coronary bypass over 20 -years, as compared to $12.6 \%$ of single IMA patients. This result is different from the Guru study, but the difference may in fact illustrate that outcomes are multivariate and interrelated. Within the U.S. healthcare system with its greater surgical availability, worse long-term results with single versus multiple arterial grafting might be manifested by a relatively higher incidence of reoperation and less of a difference in mortality. Conversely, care limitations in Canada might be associated with a lower incidence of reoperation and a higher mortality. This point emphasizes the propriety of composite outcome, but in any event, the debate about multiple IMA grafting seems to be over. Whereas, the incidence of multiple IMA grafting was low in recent STS data, the rate very likely will accelerate at this point. To modestly go out on a limb, one might even suggest that $50-75 \%$ of patients with multi-vessel disease now should be managed with multiple IMA's, including patients with diabetes and other high-risk profiles. ${ }^{34}$ It should be emphasized that this concept is not substantiated for radial artery grafts, and one IMA and concomitant radial arteries should not be considered as "all arterial" surrogates for multiple IMA grafting. Certainly, the inability to differentiate between types of arterial grafts is a weakness in the study of Guru et al, and needs to be remedied in their database. Proven clinical benefits are associated only with bilateral IMA's, and with recent radial artery patency data, it is unlikely that addition of radial arteries (while perhaps useful) will produce major therapeutic benefits.

Finally, one might traverse another limb, and propose a change in the treatment algorithm for future patients with serious multi-vessel coronary artery disease. Given the excellent long-term outcomes associated with multiple IMA grafting, and the as yet irrefuted late problems with PCI, maybe the current management strategy of attempting PCI first in most patients is backwards. Perhaps multiple IMA grafting should be performed as the first procedure in most patients with serious multi-vessel coronary obstruction, and then PCI applied for the unusual situation of graft failure and recurrent single vessel disease. It is likely that outcomes would be improved with this approach, and long-term cost efficacy also could be better. Quoting again from Dr. Kirklin's lecture over 3 decades $\mathrm{ago}^{3}$ : "If we are able to provide the best possible care for all patients coming to us with heart disease, now and in the future, we must do many things, including the continual evaluation of the results of our cardiac operations and a comparison of these results with those of other patient management programs and with the natural history of the disease". In the near future, Dr. Kirklin's vision may become everyday reality.

\section{References}

1. Carrel A. On the experimental surgery of the thoracic aorta and heart. Ann Surg. 1910;52:83.

2. Edwards WS, Edwards PD. Alexis Carrel: Visionary Surgeon. Charles Thomas, Springfield, Ill, 1974.

3. Kirklin JW. Evaluating the Results of Cardiac Surgery. Circulation. 1973;48:232-38.

4. Guru V, Fremes SE, Tu JV, et al. How many arterial grafts are enough? A population based study of mid-term outcomes. J Thorac Cardiovasc Surg; this issue.

5. Takaro T, Hultgren HN, Lipton MJ, et al. The VA randomized study of surgery for coronary artery occlusive disease. II. Subgroup with significant left main lesions. Circulation. 1976;54(Suppl 3):107-14.

6. Goligher JC, Pulvertaft CN, DeDombal FT, et al. Five- to eight-year results of Leeds-York controlled trial of elective surgery for duodenal ulcer. Brit Med J. 1968;2:781-9.

7. Cox DR. Regression models and life tables. J R Stat Soc. 1972;34: 187-202.

8. Russell RO Jr., Moraski RE, Kouchoukos NT, et al. Unstable angina pectoris: national cooperative study group to compare surgical and medical therapy. Am J Cardiol. 1978;42:840-7.

9. European coronary surgery study group: Prospective randomized study of coronary artery bypass surgery in stable angina pectoris. Lancet. 1980;2:491-9.

10. CASS Principal Investigators. Coronary artery bypass surgery: Survival data. Circulation. 1983;68:939-47.

11. Rankin JS, Newton JR Jr., Califf RM, et al. Clinical characteristics and current management of medically refractory unstable angina. Ann Surg. 1984;200:457-65.

12. Hlatky MA, Califf RM, Harrell FE, et al. Comparisons of predictions based on observational data with the results of randomized controlled clinical trials of coronary artery bypass surgery. J Am Coll Cardiol. 1988;11:237-45.

13. Califf RM, Harrell FE, Lee KL, et al. The evolution of medical and surgical therapy for coronary artery disease: a 15-year perspective. JAMA. 1989;261:2077-86.

14. Rankin JS, Smith LR, Morris JJ, Glower DD, Wechsler AS: Clinical evaluation of single vs multiple mammary artery bypass. Circulation. 80(suppl II):II-627-36, 1989.

15. Selke FW, DiMaio JM, Caplan LR, et al. Comparing on-pump and off-pump coronaryartery bypass grafting: Numerous studies but few conclusions. Circulation. 2005;111:2858-64.

16. Racz MJ, Hannan EL, Isom OW, et al. A comparison of short- and long-term outcomes after off-pump and on-pump coronary artery bypass graft surgery with sternotomy. J Am Coll Cardiol. 2004;43:557-64.

17. Williams ML, Muhlbaier LH, Schroder JN, et al. Risk-adjusted shortand long-term outcomes for on- versus off-pump coronary artery bypass surgery. Circulation. 2005;122(Suppl):I366-70.

18. Brooks MM, Jones RH, Bach RG, et al. Predictors of mortality from cardiac causes in the bypass angioplasty revascularization investigation (BARI) randomized trial and registry. For the BARI investigators. Circulation. 2000;101:2682-9.

19. Brener SJ, Lytle BW, Casserly IP, et al. Propensity analysis of longterm survival after surgical or percutaneous revascularization in patients with multivessel coronary artery disease and high-risk features. Circulation. 2004;109:2290-5.

20. Hannan EL, Racz MJ, Walford G, et al. Long-term outcomes of coronary bypass grafting versus stent implantation. $N$ Eng J Med. 2005;352:2174-83

21. O'Rourke DJ, Quinton HB, Piper W, et al. Survival in patients with peripheral vascular disease after percutaneous coronary intervention 
and coronary artery bypass graft surgery. Ann Thorac Surg. 2004; 78:466-70

22. Smith PK, Califf RM, Tuttle R, et al. Selection of surgical or percutaneous coronary intervention provides longevity benefit that varies with the severity of coronary disease. Presented at the January 2006 STS meeting, Chicago Ill., and submitted to Ann Thorac Surg.

23. Katz MR, Van Praet F, de Canniere D, et al. Integrated coronary revascularization: Percutaneous coronary intervention plus robotic total endoscopic coronary artery bypass. Presented at the American Heart Association meeting, November 2005, and submitted to Circulation.

24. Lytle BW, Blackstone EH, Loop FD, et al. Two internal thoracic arteries are better than one. J Thorac Cardiovasc Surg. 1999;117:855-72.

25. Lytle BW, Blackstone EH, Sabik JF, et al. The effect of bilateral internal thoracic artery grafting on survival during 20 postoperative years. Ann Thorac Surg. 2004;78:2005-14.

26. Rosenbaum PR, Rubin D. The central role of the propensity score in observational studies. Biometrika. 1983;70:41-55.

27. D'Agostino RB, Kwan H. Measuring effectiveness: what to expect without a randomized control group. Medical Care. 1995;33:AS95AS105.
28. Mark DB, Nelson CL, Califf RM, et al. The continuing evolution of therapy for coronary artery disease. Circulation. 1994;89:2015-25.

29. Blackstone EH, Lytle BW. Competing risks after coronary bypass surgery: the influence of death on reintervention. J Thorac Cardiovasc Surg. 2000;119:1221-30.

30. Lavori PW, Dawson R, Mueller TB. Causal estimation of time-varying treatment effects in observational studies. Stat in Med. 1994;13:10891100 .

31. Robins J. The control of confounding by intermediate variables. Stat in Med. 1989;8:679-701.

32. Brumback B, Greenland S, Redman M, et al. The intensity score approach to adjusting for confounding. Biometrics. 2003;59:274-85.

33. Burfeind WR Jr., Glower DD, Wechsler AS, et al. Single versus multiple internal mammary artery grafting for coronary artery bypass: 15-year follow-up of a clinical practice trial. Circulation. 2004;110 (Suppl II):II27-II35.

34. Rankin JS, Tuttle RH, Wechsler AS, et al. Techniques and benefits of multiple internal mammary artery bypass at 20-years of followup. Presented at the January 2006 STS meeting, Chicago Ill., and submitted to Ann Thorac Surg.

\section{The Journal of Thoracic and Cardiovascular Surgery Conflict of Interest Policy}

To assure fairness to authors submitting work for consideration in The Journal of Thoracic and Cardiovascular Surgery, a mechanism exists for managing conflicts of interest. The editor and each of the section editors complete a "Conflict of Interest" form that identifies any and all relationships with commercial and other academic entities. When the editor has a potential conflict because of a relationship with another entity or author, the editor appoints an alternate editor from among the section editors or editorial board members who assumes the entire responsibility for final decisions on the manuscript in question. The editor does not read the reviews that are submitted nor engage in discussing the manuscript prior to the final decision. When the conflict of interest involves a section editor, a "guest section editor" is appointed who fills the role normally played by the conflicted section editor. All members of the editorial board and reviewers are asked to indicate any conflict of interest when they agree to review a manuscript. 